\title{
Assessment and Inventory of Forest Ecosystems Biodiversity: Case Study for Karelian Isthmus of Leningrad Region, Russia
}

\author{
Alexander S. Alekseev \\ Department of Forest Inventory, Management and GIS, Sankt-Petersburg State Forest Technical University, Sankt-Petersburg, \\ Russia \\ Email: a_s_alekseev@mail.ru
}

How to cite this paper: Alekseev, A.S. (2018) Assessment and Inventory of Forest Ecosystems Biodiversity: Case Study for Karelian Isthmus of Leningrad Region, Russia. Open Journal of Ecology, 8, 305-323. https://doi.org/10.4236/oje.2018.85019

Received: April 5, 2018

Accepted: May 14, 2018

Published: May 17, 2018

Copyright $\odot 2018$ by author and Scientific Research Publishing Inc. This work is licensed under the Creative Commons Attribution International License (CC BY 4.0).

http://creativecommons.org/licenses/by/4.0/

\section{(c) () Open Access}

\begin{abstract}
Regular grid of permanent sample plots (PSP) of ICP-Forests monitoring system was used for forest ecosystems biodiversity assessments and inventory. The supplementary features were added to the PSP structure to conduct biological diversity census: eight sample plots $1 \times 1 \mathrm{~m}$ for geo-botanical description; two sample plots of $5 \times 5 \mathrm{~m}$ each for description of the PSP's undergrowth; one $25 \times 25 \mathrm{~m}$ plot for coarse woody debris estimations; four soil inventory pits. The total number of PSP amounted to 248 . Total data used are as following: 1) 1984 geo-botanical descriptions of vegetation belonging to ground cover layers made on $1 \times 1 \mathrm{~m}$ sample plots; 2) 496 descriptions of undergrowth on $5 \times 5 \mathrm{~m}$ sample plots; 3) 178 descriptions of woody debris on 25 $\times 25$ m sample plots; 4) 496 descriptions of soil inventory pits. General statistical indicators characterizing forest land cover diversity were calculated. Statistic indicators of $\alpha$-diversity for the Karelian Isthmus forest vegetation cover have the following values: 1$) \mathrm{m}$ (mean number of species per PSP) $=26$ species; 2) $\sigma$ (standard deviation $)=9.5$ species; 3$) \mathrm{v}($ variation coefficient $)=$ $36.5 \%$; 4) $\mathrm{P}$ (deviation amplitude) $=60-7=53$ species. $\beta$ - diversity of forest ecosystems as well as $\gamma$-diversity also was studied on the base of information collected on the same regular grid of sample plots. It appears that sample plots distribution by species diversity gradation is well described by the standard curve of normal distribution for the entire Karelian Isthmus forest (determination coefficient of the curve being 95.2\%) as well as for each type of forest. Hence, the criterion (standard) of biodiversity for forest ecosystems can be defined as the mean value of alpha diversity for each forest type group - $\mathrm{m}$; and the standard deviation $-\sigma$, as a tool for assessing deviations from the standard. PSP locations are fixed using GPS technology, this allows biodiversity assessments at the same place in the next years for biodiversity trends es-
\end{abstract}


timations and consist the frame for systematic biodiversity inventory.

\section{Keywords}

Plant Biodiversity, ICP-Forests Program, Forest Ecosystems, $\alpha$-, $\beta$-, $\gamma$-Diversity, Regular Grid of Sample Plots, Biodiversity Standards.

\section{Introduction}

Today the society is becoming increasingly aware of the fact that, due to protracted and careless exploitation of natural resources, it irretrievably loses natural complexes and many animal and plant species as these species cannot exist outside their natural ecosystems [1]. Forest ecosystems are known for sheltering the greatest biodiversity by comparison with many other ecosystems located in the same climatic zone. Biologists and ecologists have actively discussed the problem of conserving biodiversity during the past few years [2] [3] [4]. Biodiversity of forest ecosystems aroused great interest in Western Europe and due to a long-run and intensive commercial exploitation of forest directed to maximal wood production, forests in these countries have in majority lost their primeval appearance. Climax forests in Europe remain only in the northern part of Russia (in Karelia and Komi republics as well as in Murmansk and Arkhangelsk regions). These forests focus the attention of researchers from Western Europe, in particular those coming from countries with close climatic conditions as Finland or Sweden. Laws, conventions, and agreements concerning different aspects of biodiversity conservation problem have been elaborated at an international level and ratified by a number of countries. Moreover, every country has its own laws and rules devoted to this question. However, all the problems concerning biodiversity conservation are not solved. There is still no common opinion about the species that are really necessary for the regular functioning of ecosystems and, therefore, that should be protected and conserved in priority [5] [6] [7]. Local conditions and the various ecosystems existing at the scale of a region play a great role as each of these ecosystems possesses its own species diversity to be preserved. At the time, the problem of conserving the biodiversity attracts so much attention, it seems necessary to formulate and ground clearly the concept of biodiversity. How can it be defined, how can it be measured in order to support practical measures for its monitoring, protection and conservation? At present, the most experienced method for biodiversity conservation is, by no means, the development of protected natural areas network. Such networks exist in many countries, but protected areas have limitation in size or statuses and cannot account for the conservation of all unique habitats. Moreover, these areas may not be indefinitely increased. Forest resources can be regenerated but still require rational and careful utilization [8].

Biodiversity assessment is mandatory for the implementation of any sustainable forest management policy and, as a fact, is included in the number of criteria 
and indicators currently in use [9]-[14].

Today we should look for forest ecosystems managing methods that would guarantee the conservation of their biodiversity and by the same time, allow local communities to benefit from forest resources. Attention should also be paid to the so called alternative forest utilization turn toward recreational, educational, scientific purposes. The Cape Biodiversity project has been implemented as an attempt to bring solutions to these problems. The project was organized and implemented in Saint Petersburg thanks to the financial support of the Life-Third Counties Program of the European Union. Russian, French, and Finnish experts took part in its implementation. The project allowed studying the vegetative biodiversity of the forest ecosystems situated on the Karelian Isthmus in Leningrad region. As a result, extensive experimental data were gathered that have been used for proposing coherent biodiversity protection policies and also for scientific and educational purposes [29] [30]. Before starting any analysis, basic terms have to be defined in order to facilitate the comprehension of the main scientific concepts.

Biodiversity is all life on earth; it is the number, variety and variability of living organisms [15] [16]. In general, there are three categorical levels of biodiversity: genetic, taxonomic, and ecological.

Genetic biodiversity involves populations, individuals, chromosomes, genes and nucleotides. Very little is known of genetic biodiversity, though it is contended that all other aspects of biodiversity are a consequence of genetic makeup.

Taxonomic biodiversity can include kingdoms, phyla, orders, families, genera, species, subspecies and populations. For practical reasons, the most commonly used taxonomic diversity measure is species diversity.

Ecological diversity considers the diversity of habitats on which individuals within a species depend on for their own unique niches that they occupy within the ecosystem. For instance, some studies focus on the importance of either structural diversity or functional diversity in forested ecosystems. Structural diversity is the vertical or horizontal distribution of plants; functional diversity covers nutrient cycling, energy flows and trophic-level relationships. Finally, one should also consider the temporal scale of diversity, since species diversity shows distinctive changes in the biotic community during different several stages of successions [17].

Ecosystem is composed of the living organisms of a particular habitat, such as a pond or forest, together with the physical environment in which they live. Ecosystems are dynamic complex of plant, animal, fungal, and micro-organism communities and their associated abiotic environment interacting as an ecological unit. Ecosystems have no fixed boundaries; instead, their parameters are set according to the scientific, management, or policy question being examined. Depending upon the purpose of analysis, a single lake, a watershed, or an entire region could be an ecosystem.

Biological diversity evaluation may be conducted at different levels using 
adapted and fundamentally different methods. The scale of the study may be as different as biosphere, continent, vegetation zones and sub-zones (geographical or climatic), region (sector), landscape, ecosystem, parcel, etc.

As the study concerns the territory of the Karelian Isthmus in Leningrad region, mainly landscape and habitat levels will be considered; habitat remaining the reference level throughout the study.

Geographic landscape is an ecological system (geosystem, natural territorial complex) where predominate homogenous, interrelated, structurally and metabolically interdependent combination of relief forms, soils, microclimates, hydrographical network, flora and fauna located under the same climatic conditions. Every type of landscape differentiates by the specific interrelations occurring between lower-level components, i.e. ecosystems, and between ecosystems' own components. Each type of landscape is a heterogeneous area composed of a cluster of interacting ecosystems that is repeated in similar form throughout: relief, types, and kinds of soils, structure and density of the hydrographical network, types of microclimate, particular fauna and flora.

The Karelian Isthmus shelters nine different types of landscapes. On such a small area this quantity indicates a great diversity of soil, hydrological, geological and biological conditions.

Habitat is, according to the well-known definition of Sukachev (1964), defined as the totality of similar natural factors (atmospheric, geologic, biotic-flora, fauna, and micro-organisms-edaphic, hydrological) occurring in a particular area, characterized by specific interactions and exchange of energy among its components, and between its components and external ones belonging to other habitats. Habitats are units constantly evolving and developing.

Such indicators as age, composition, productivity, patchiness, frequency of occurrence, stage in the succession process, quantity, and resources may be considered or used for assessing biodiversity. Theoretically, whatever the level the biodiversity is assessed, this assessment may concern all of its elements. However, the following combinations are usually the practical significance: at a scale of an ecoregion or a landscape, biodiversity assessment will consider habitat diversity, diversity of the fauna and flora; at a scale of a forest habitat, diversity of habitat structure (number of canopy layers) and diversity of the flora (first of all of forest-generating tree species), structure of tree species population.

Assessment of the biodiversity of Karelian Isthmus forest ecosystems was carried out according to the diversity of habitats, displayed in their turn by forest type diversity, and diversity of vegetation species and populations observed over the investigated area [18] [19] [20].

\section{Material and Methods}

As field investigations had to cover an area as large as the Karelian Isthmus, the existing grid of sample plots for bio-indicator and ecological monitoring of forests, created in the frame of the ICP-Forest program, was chosen as a basis for 
organizing field works [21].

The Karelian Isthmus is an area of land between the Gulf of Finland and Ladoga Lake. The southern border of the Karelian Isthmus is the Neva River, and the Northern border runs along the line of Russian-Finnish border. Geographically, this area is approximately between $61^{\circ} 21^{\prime}$ and $59^{\circ} 46^{\prime}$ North latitude and $27^{\circ} 42^{\prime}$ and $31^{\circ} 08^{\prime}$ East longitude. From North to South the length of the isthmus is $150-180 \mathrm{~km}$, from West to East $55-110 \mathrm{~km}$.

Regular grids of sample plots for bio-indicators are the most simple and intelligible way to select model trees in some given area according to strict and simple rules. Appliance of such rules allows considering that the selection remains haphazardly. In case investigated sample plots are sufficient enough in quantity, obtained conclusions on the state of forests for the given area would be regarded statistically proved.

The research period was extended in time. In 1995, a regular network of PSP according ICP-Forests methodology was established. In 2000, it was made denser for Karelian Isthmus and modified for plants biodiversity assessment and inventory. The analysis of the collected data and discussion of results is still ongoing.

\subsection{Regular Grid of Permanent Sample Plot (PSP) for Assessing Vegetation Biological Diversity of the Main Forest Types on Karelian Isthmus}

As was mentioned above, ecosystems should be considered the main structural level for assessing biological diversity on Karelian Isthmus. Ecosystems most important components are the diversity of forest types as well as the species and populations composition displayed on the investigated area.

Determining to which taxonomic group the vegetative community belongs to during field work is very important. Such approach is paramount for choosing PSP location. Areas are heterogeneous by structure and composition. Such heterogeneity conditions the degree of variation of the vegetation cover. Knowing the typical characteristics of different types of forest ecosystems allows escaping mistakes when choosing PSP location. Secondly, gathering all the necessary characteristics describing a type of forest community can be carried out only during field survey.

The forest type classification edited by St. Petersburg Forest Research Institute as well as forest management schemes (forest type groups) were used as basis for planning the collection, analysis, and processing of the data [18] [19]. Seven groups of forest types have been determined and investigated on the Karelian Isthmus: lichen $(\mathrm{Lch})$, cowberry $(\mathrm{Cb})$, oxalis $(\mathrm{Ox})$, bilberry $(\mathrm{Bl})$, polytrichosum $(\mathrm{Pt})$, sphagnum $(\mathrm{Sph})$, and motley grass $(\mathrm{Mg})$.

These forest type groups essentially differ by their most important ecological characteristics, such as nutrient availability, which is necessary for plant growth and development, trophic factors, and moistening. Admittedly, these two factors-trophics and moistening-determine the potential of forest habitats 
productivity. Lichen and cowberry groups are characterized by dry and poor habitats, the first one even more than the second. Oxalis, bilberry, Polytrichosum and sphagnum groups of forest types are, respectively, characterised by a diminution in trophic resources and an increase of stagnant moistening. Motley grass forest type group is represented by habitats having optimal characteristics both for trophic resources and moistening.

Field work planning took into account forest management data, particularly the area under each forest type group on the Karelian Isthmus. This information allowed calculating the necessary number of PSP for each forest type group. Processing of biodiversity indexes and estimates of anthropogenic influence on forest ecosystems were also conducted according to forest type groups. On the basis of forest management data, seven representative forest type groups were retained. Herbaceous-swamp and riverside-motley grass groups were united into one group owing to growing condition similarities.

Forest type series elaborated by St. Petersburg Forest Research Institute were used for the following operations: for a more precise ecological assessment of each PSP during their description and data processing, and later on for attributing PSP to the forest type groups according to forest management data; for analyzing species vegetation diversity level and its changes under the influence of various factors. The determination of forest type series was carried out according to groups of indicator species and particular characteristics such as location on the relief and edaphic conditions. These lasts described soil substrate layers, soil structure, and organic layer thickness.

The quantity of PSP to be investigated that guarantees a sufficient statistical representative number amounted to 248. PSP formerly used for forest monitoring were also used for the present work in case they were situated on intersection points of the grid.

For assessing anthropogenic impacts using bioindicators it has been necessary to locate PSP in the most sensible forest type groups (for example, Lichen one). Following, the number of PSP allocated to sensitive forest groups was not proportional but superior to their respective share of the forest area.

\subsection{Modification Brought to PSP Scheme for Biodiversity Census}

A PSP center has to be located not farther than $0.5 \mathrm{~km}$ from grid-referenced coordinates and no closer than 35 - 40 meters from inventory compartment's edge, forest's outskirts, road, or electric line. To ease orientation, PSP have to be located near easily recognizable features such as forest quadrate cuttings, paths, drainage ditches, or roads. Distance to these reference points is measured using tape or steps. Measurement starting point and orientation to be followed are identified by special marks (e.g. the central tree by oil paint). Geo-referencing is registered on the data record sheet showing magnetic bearing and distance to the centre of the PSP. In case no tree may be used as PSP centre, a small stake was dug into the ground in order to find it easily during the next investigation cam- 
paign. Four census points (CP) are put on each PSP following cardinal points direction, at a distance of 25 meters from the central (axial) tree, and numbered: 1 for North, 2 for East, 3 for South, and 4 for West. A small $0.5-0.7$ meters high stake is dug into the ground in the center of the $\mathrm{CP}$. The following supplementary features were added to the PSP structure especially to conduct biological diversity census: 1 ) Eight sample plots $1 \times 1 \mathrm{~m}$ for geo-botanical description of herbaceous-shrubby and moss-lichen vegetation layers. Two plots are situated in each census point (CP): one point in the center of the $\mathrm{CP}$ and another one at a distance of 7.07 meters within the PSP and forming a diagonal of $5 \times 5 \mathrm{~m}$ square. 2) Two sample plots of $5 \times 5 \mathrm{~m}$ each for geo-botanical description of the PSP's undergrowth. The plots are situated in the northern and southern parts of the PSP. 3) A $25 \times 25$ m plot for coarse woody debris census situated in the north-western quarter of the PSP. Moreover, four soil inventory pits were dug to provide a more detailed description of edaphic characteristics and forest types. Modified PSP scheme for biodiversity census presented on Figure 1.

Theoretically, the above mentioned scheme used for biodiversity census is close to the one used by American forest monitoring system for describing the state of the vegetation (Forest Health Monitoring). The total number of PSP laid on the Karelian Isthmus in the frame of the project amounted to 248. Ancillary data used for processing, analyzing, developing the data base, and elaborating

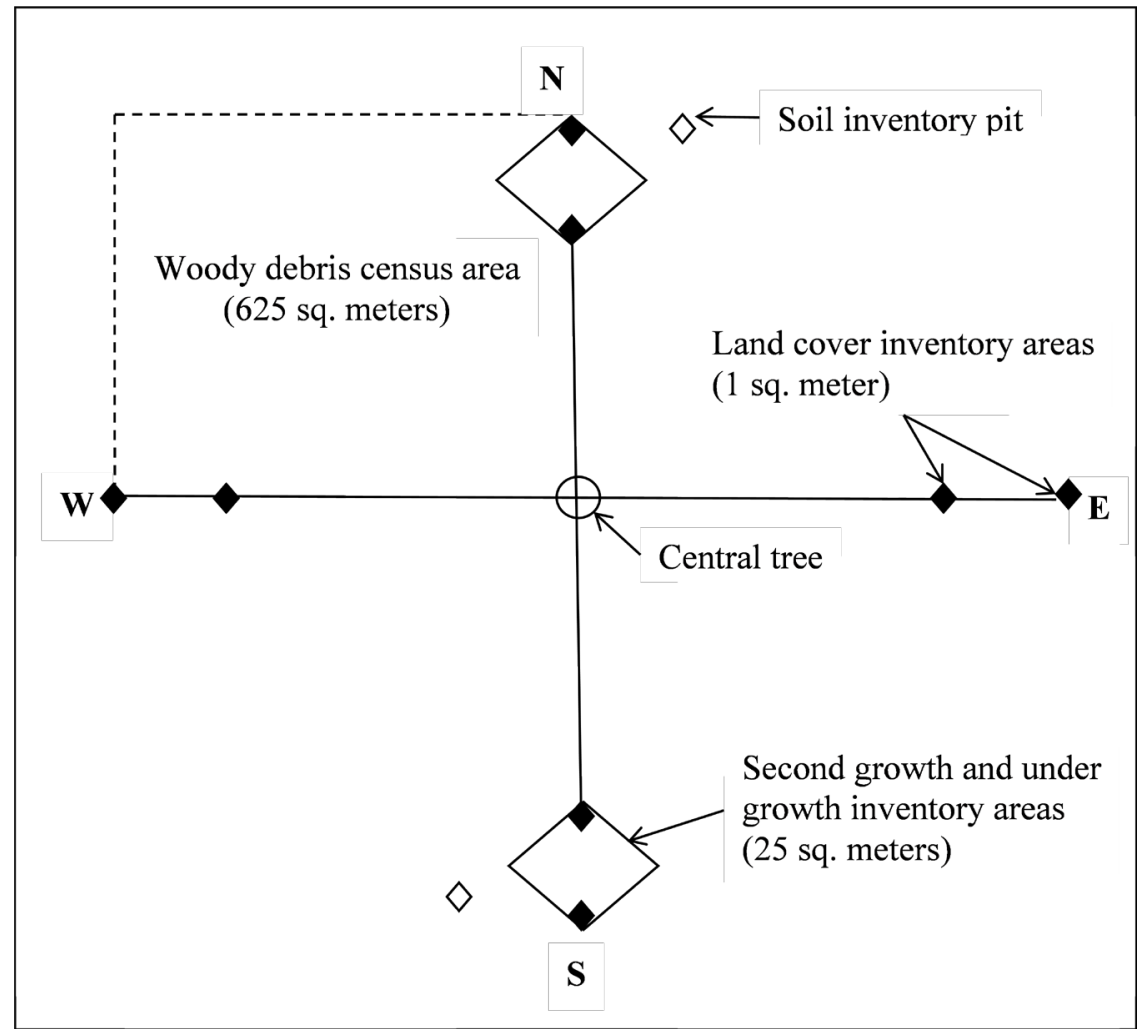

Figure 1. Modified scheme of permanent sample plot (PSP) as used in regional grid for monitoring of forests. 
the geographic information system are the following:

- 1984 geo-botanical descriptions of vegetation belonging to herbaceous-shrubby and moss-lichen layers made on $1 \times 1 \mathrm{~m}$ sample plots;

- 496 descriptions of undergrowth on $5 \times 5 \mathrm{~m}$ sample plots;

- 178 descriptions of woody debris on $25 \times 25 \mathrm{~m}$ sample plots (the description is systematically conducted on each plots);

- 496 descriptions of soil inventory pits.

According to preliminary assessment, such volume of field data gathered on regular bio-indicator grid following haphazardly method is enough for reliably assessing the biological diversity of the Karelian Isthmus and for estimating anthropogenic impact intensity.

\section{Results and Discussions}

\subsection{General Description of Alpha-Diversity of Forest Vegetation Cover}

Alpha diversity represents the variety of plant species found within a particular forest ecosystem and measured by the number of dwelled plant species or by the Simpson index that considers both the number of species and their relative variety [22] [23]. Alpha-diversity was evaluated by forest type series that were distinguished from each other according to forest habitat characteristics. At first, general statistical indicators characterizing forest land cover diversity were calculated. The following symbols were used:

- $n_{i}$-species variety of forest land cover on i sample plot;

- $n$-total number of sample plots;

- $m=\frac{\sum_{i=1}^{n} n_{i}}{n}$-average number of species per sample plot;

- $\sigma=\sqrt{\frac{\sum_{i=1}^{n}\left(n_{i}-m\right)^{2}}{n-1}}$-mean square deviation from mean value of species number per sample plot;

- $v=\frac{m}{\sigma} * 100 \%$-variation coefficient of species number per sample plot as a percentage from the mean value;

- $P=\max \left(n_{i}\right)-\min \left(n_{i}\right)$-deviation amplitude of species variety between maximum and minimum values.

Statistic indicators of $\alpha$-diversity for the Karelian Isthmus forest vegetation cover have the following values:

$$
\begin{aligned}
& m=26 \text { species; } \\
& \sigma=9.5 \text { species; } \\
& V=36.5 \% ; \\
& P=60-7=53 \text { species. }
\end{aligned}
$$

Alpha-diversity statistics significantly varies over the territory of the Karelian Isthmus. Amplitude of deviation in species variety amounts to 53 species that is twice as much as the mean value. The largest species variety exceeds almost by 9 
times the smallest one.

The largest species diversity is found in oxalis forest type group, habitats considered as having optimal conditions. The poorest diversity is found in bilberry and cowberry forest type groups. Sample plots' distribution (or share) according to species diversity gradation is well described by standard curve of normal distribution (determination coefficient of the curve being 95.2\%). Computations of average and average quadratic deviations stated above show that the number of species ranges from 15 up to 35 in $65.7 \%$ of the sample plots. According to standard curve of normal distribution, this number should amount to $68.3 \%$ that is close to the experimental data. Moreover, experimental results show an asymmetry in the distribution, i.e. sample plots with species variety less than average are dominating.

Forest species diversity on the Karelian Isthmus is relatively small, ranging from 15 to 35 species in almost $2 / 3$ of the cases that is typical for the south taiga zone.

Karelian Isthmus forest ecosystem diversity according to dominating species is given on Figure 2.

Figure 2 shows that species diversity is the largest in forest ecosystems where deciduous species, as birch and aspen, predominate. In stands where coniferous species dominate, pine and spruce, species diversity is almost the same and amounts to 24 species on average, a little less than the average value for the whole Karelian Isthmus.

In stands where birch and aspen species predominate diversity reaches respectively 35 and 39 species. These values are much higher than the average for Karelian Isthmus and $40 \%$ higher than values for coniferous stands.

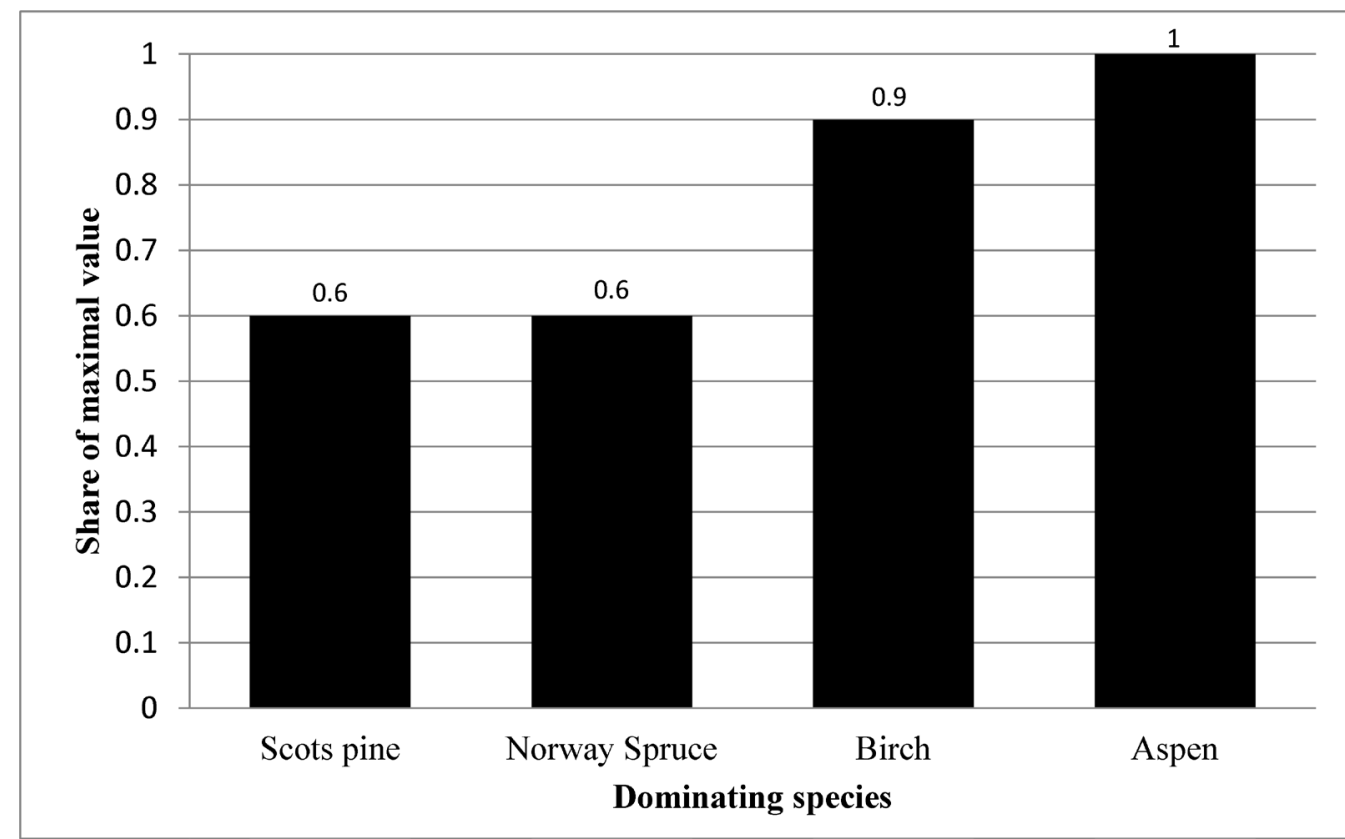

Figure 2. Forest ecosystem alpha-diversity according to dominating species measured as a share of maximum value. 
Results of the dispersion analysis also show the absence of reliable relationship between species diversity of forest ecosystems on the one hand, and density and age of stand predominating species on the other hand. Such a result was unexpected, especially taking into account the fact that lower canopy layers contribute the most to vegetative diversity, and that their living conditions strongly depend on characteristics of the main tree layer. Figure 3 and Figure 4 show relationship between forest ecosystems alpha diversity and density and age of the predominating species.

The fact that relative constancy of average number of species in forest ecosystems does not depend on density and age of predominating tree species may be explained by peculiarities of the analysis carried out: it considered only stands

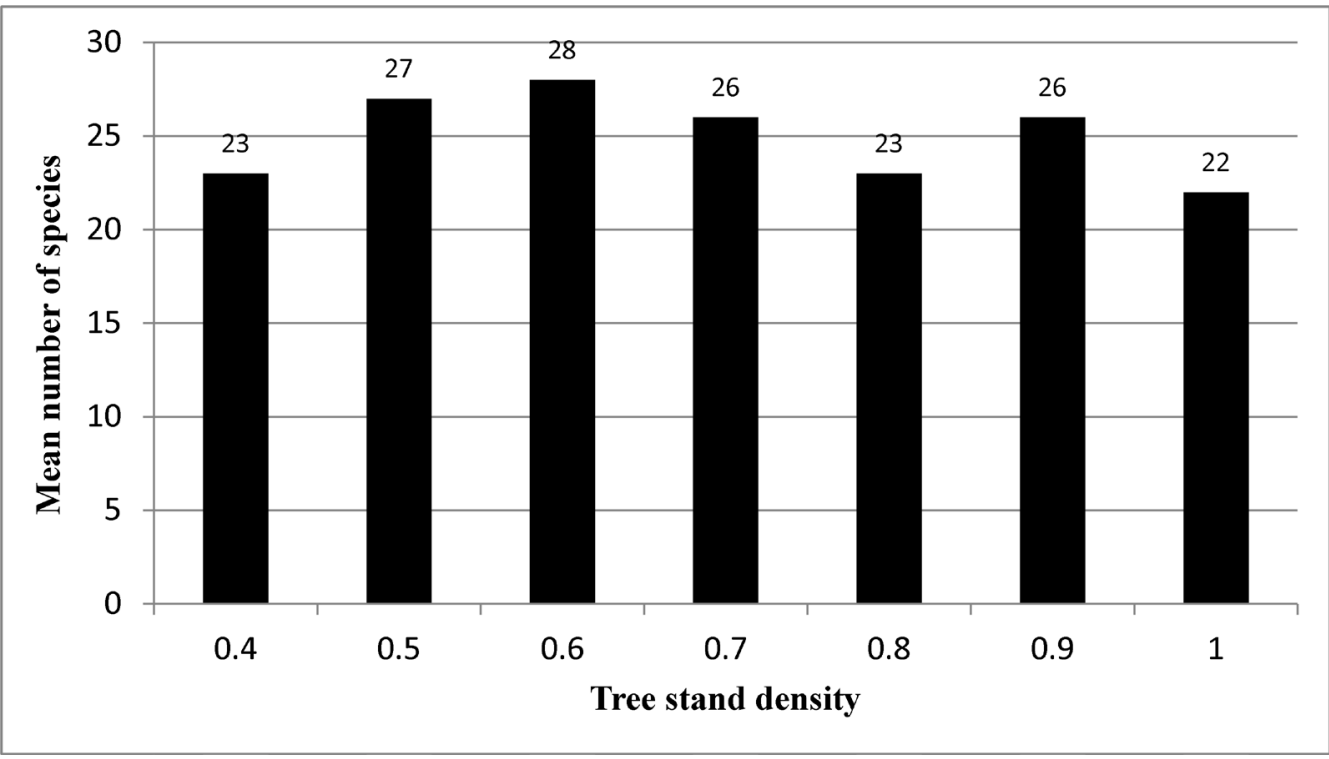

Figure 3. Forest ecosystem alpha-diversity with respect to tree stands density of dominating species.

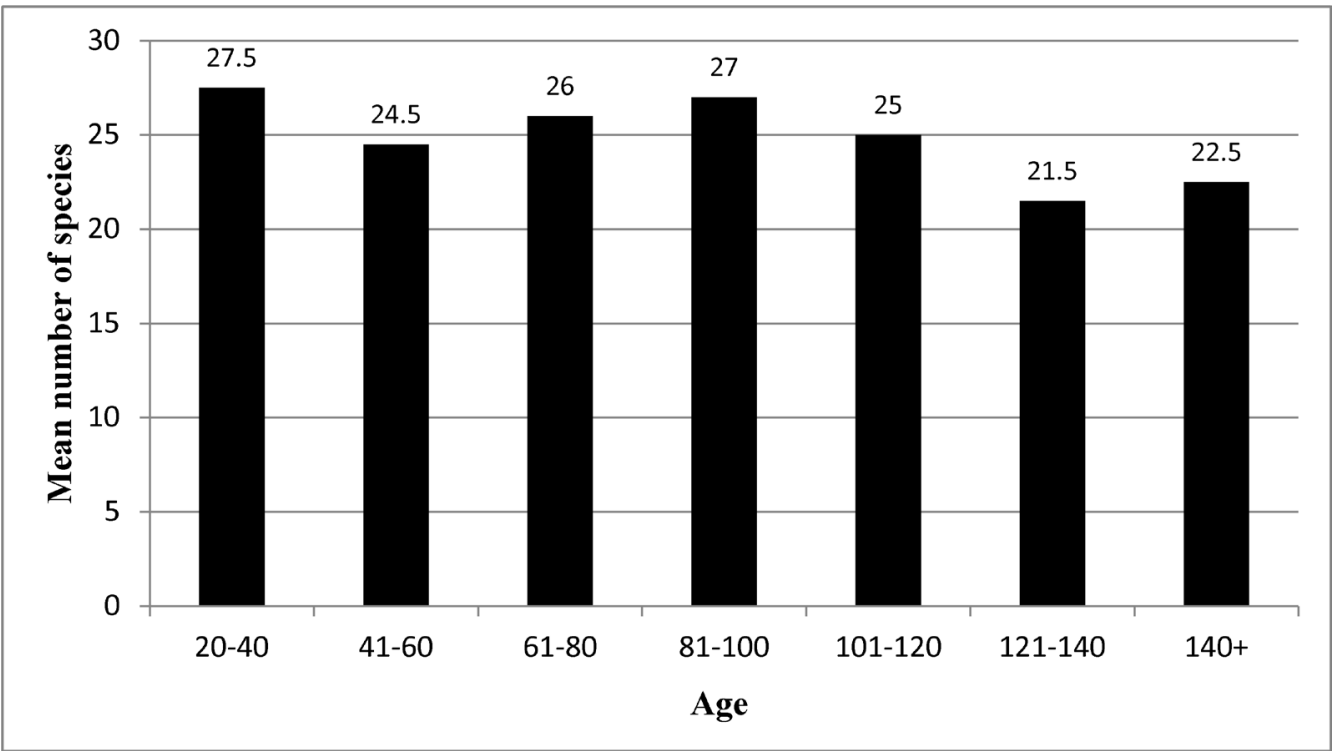

Figure 4. Forest ecosystem alpha-diversity with respect to age of dominating species. 
with density from 0.4 to 1.0 , i.e. sparse stands were not taken into account. On the other hand, this fact may be explained from the point of view of ecological niche concept [23] [24] [25] [26] [27], which stipulate that resources allowable for plant development at a particular place are always used completely. Proceeding from his concept, it may be supposed that, in the relatively poor forest habitats of the Karelian Isthmus and under intensive concurrence for resources, changes in density and age of tree stands drive to changes in occurrence and relative abundance and coverage of plant species, but that the resulting number of species remains the same. In case these preliminary conclusions concerning the relative constancy in average of plant species number under a wide spectrum of forest ecosystems conditions would be confirmed, it noticeably increases scientific and practical significance of alpha-diversity index for ecological monitoring and sustainable forest management. Indirect confirmation of such assertion could be that strong and statistically reliable relationship has been found for ecosystems between alpha diversity and forest type groups. These last differ essentially by trophic and moistening conditions and, subsequently, by the number of ecological niches.

\section{2. $\beta$-Diversity of Forest Vegetation Cover}

Beta-diversity represents the species diversity of the vegetation cover associates with changes in sample composition along a gradient of the most significant environmental factors. Statistics obtained as a result of field observations allow evaluating beta-diversity indicator for each forest ecosystem belonging to different forest type groups [28].

Seven groups of forest types have been determined and investigated on the Karelian Isthmus: lichen (Lch), cowberry (Cb), oxalis (Ox), bilberry (Bl), Polytrichosum (Pt), sphagnum (Sph), and motley grass $(\mathrm{Mg})$.

These forest type groups essentially differ by their most important ecological characteristics, such as nutrient availability, which is necessary for plant growth and development, trophic factors, and moistening. Admittedly, these two factors-trophics and moistening-determine the potential of forest habitats productivity. Lichen and cowberry groups are characterized by dry and poor habitats, the first one even more than the second. Oxalis, bilberry, Polytrichosum and sphagnum groups of forest types are, respectively, characterized by a diminution in trophic resources and an increase of stagnant moistening. Motley grass forest type group is represented by habitats having optimal characteristics both for trophics resources and moistening. Table 1 gives the average number of species in ecosystems belonging to different forest type groups, and also the total number of investigated test areas by forest type groups.

Usually beta-diversity is expressed in relative units. On Figure 5, beta-diversity is expressed for each forest type group by comparison to the Oxalis forest type group, i.e. the richest one. According to the information presented in Table 1 and on Figure 5, species diversity of Karelian Isthmus strongly depends on 
Table 1. Average number of species in ecosystems belonging to different forest type groups.

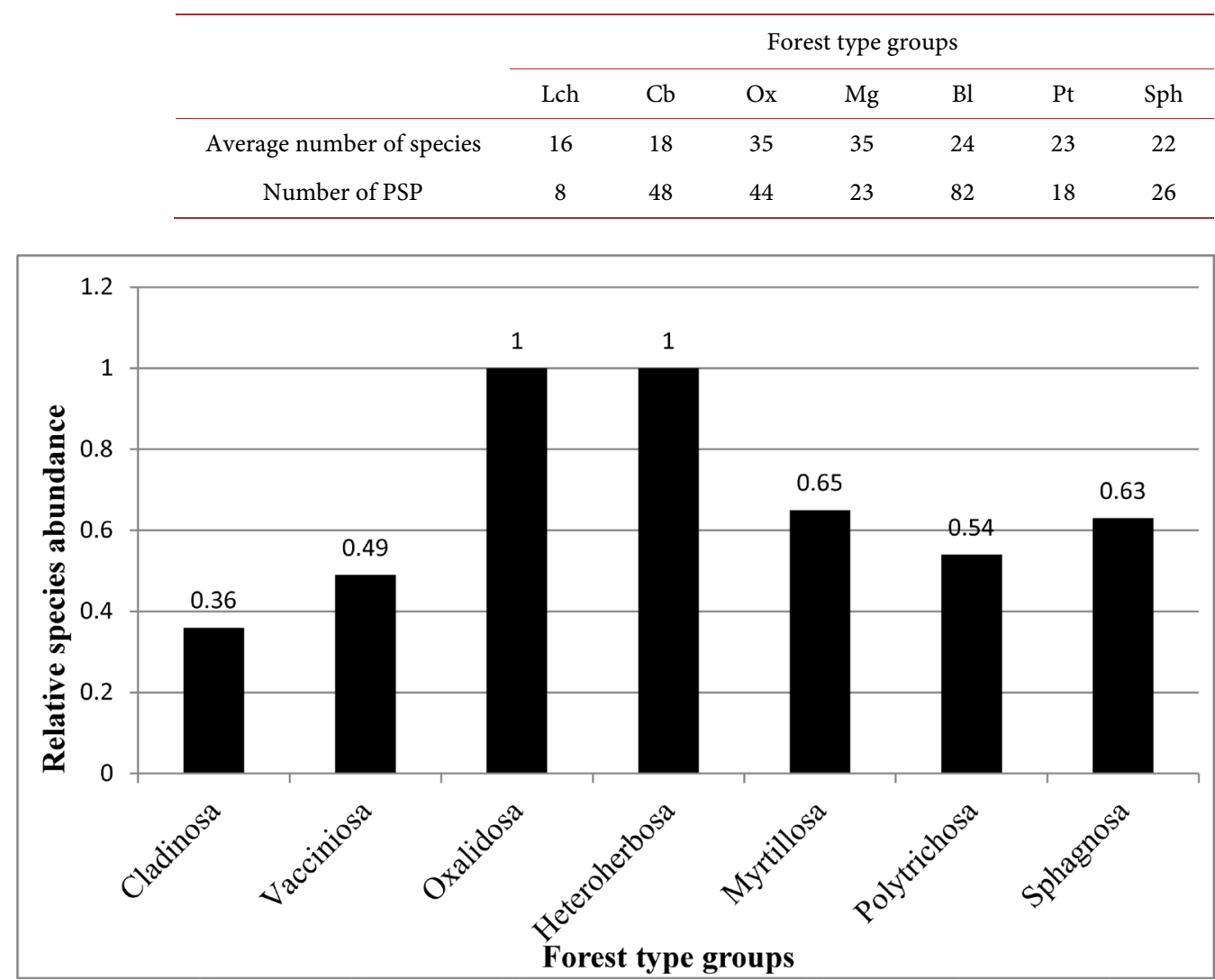

Figure 5. Beta-diversity of the forest vegetation cover of Karelian Isthmus measured as a share of maximum value.

which forest type group the forest ecosystem belongs to, that is to say on trophic and moistening factors, i.e. the most important ecological factors determining growth and development of plants.

The largest species diversity may be observed in rich and optimally moistened habitats, the least one in dry and poor ones, and middle diversity in moist habitats. Trophic and moisture factors strictly condition forest communities' biodiversity.

\section{3. $\gamma$-Diversity of Forest Vegetation Cover}

Gamma-diversity represents the comparative analysis of forest vegetation cover diversity indexes when they are combined by landscape units. The Karelian Isthmus has been divided into nine main landscape units: Vyborg; North-west Priladozhie; Primorsky north-coast; Privuoxa; Otradnensky; Upper Okhta; Lembolovo; Prinevsky; and Southern Priladoga. As for beta-diversity, gamma-diversity is usually expressed in relative units. Gamma diversity of forest vegetation cover by basic landscape units is shown on Figure 6 in comparison to the richest landscape North-west Priladoga.

According to the information presented in Figure 6, the nine landscape units 


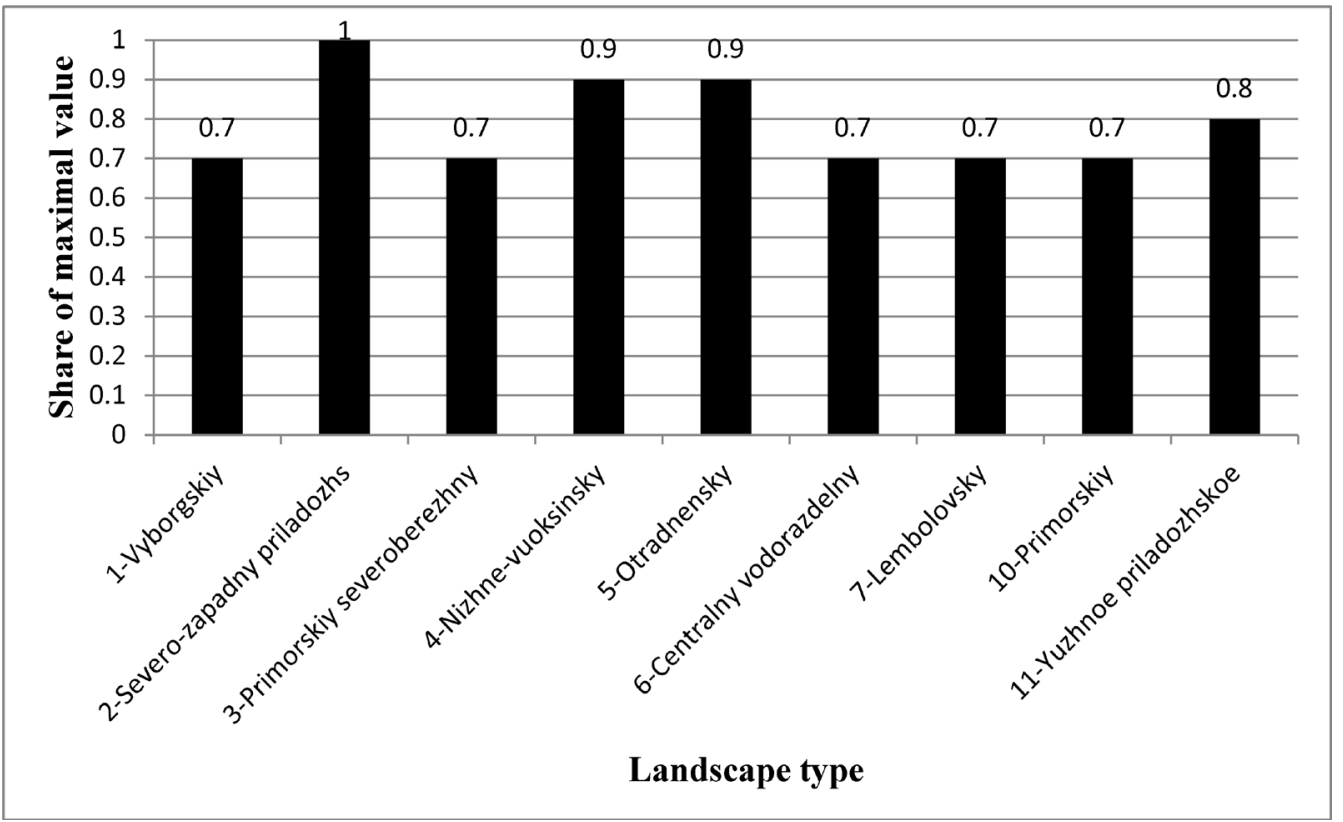

Figure 6. Gamma-diversity of the forest vegetation cover of Karelian Isthmus measured as a share of maximum value.

are characterized by approximately the same species diversity.

On the whole, variations in vegetation biodiversity by type of landscapes are nearly twice less (from 0.7 to 1.0 ) than by groups of forest types (from 0.4 to 1.0). This is due to the fact that landscapes are large and heterogeneous units and include forest ecosystems belonging to different forest type groups.

\subsection{Standards of Vegetation Diversity According to Karelian Isthmus Forest Types Groups}

Solving the problem of sustainable forest management, including the conservation of biological diversity as one of its most important component, lead to the fulfillment several tasks. It requires at first to quantify forest ecosystems biodiversity for the studied region, and, at second, to assess biodiversity indicators in terms of "normal" or "pathological". In other words, biodiversity assessment of one or another ecosystem should lead to qualitative conclusion to express whether the state of this ecosystem may be qualified as normal or not. In case it deviates from the normality, appreciation of deviation significance should be given.

Without such assessment using biodiversity indicators for sustainable forest management would be problematic. In order to solve this problem, the concept of vegetation biodiversity standard has to be introduced.

Vegetation biodiversity standards will also be necessary for organizing forest monitoring rationally. Forest monitoring that uses bio-indicator grids is a very good basis for precisely and quantitatively determining biodiversity indicators on geo-referenced sample plots, as already shown by the method described above. In this case, biodiversity standards will be necessary for assessing biodi- 
versity dynamics in time and space. The most appropriate natural feature for determining biodiversity standard is forest type group. This is due to the fact that, as shown by investigations' results, alpha-diversity of forest ecosystems mostly depends from the forest type group they belong to. Thus, alpha diversity variations are the largest among different forest type groups. Moreover, forest type groups are characterized by indicators that are necessarily defined both during sample plots investigations and forest management activities. Therefore, information that forest stands belong to one or another forest type group is well known and available.

Biodiversity standards may be verified by gathering qualitative data on forest ecosystems biodiversity for particular regions. Particularly, while determining the standards it would be possible to substitute forest type groups as the basic natural object for forest types that take into account differences between forest ecosystems consisting in the main forest forming species.

As shown by the researches, forest cover vegetation diversity measured by the number of species, i.e. alpha-diversity is a changeable indicator depending on a number of factors, of which the most important is the forest type group the ecosystem belongs to.

However, biodiversity also varies within forest type groups. Analysis of these changes has shown that it can be described precisely enough by a curve of normal distribution:

$$
f(x)=\frac{1}{\sigma \sqrt{2 \pi}} * \mathrm{e}^{-\frac{(x-m)^{2}}{2 * \sigma^{2}}}
$$

where,

$x$-value of vegetation cover alpha-diversity,

$f(x)$-probability that a forest ecosystem belonging to a particular forest type group has an alpha-diversity equal to $x$,

$m$-mean alpha-diversity of forest ecosystems belonging to a particular forest type group,

$\sigma$-average quadratic (standard) deviation from the mean value of alpha-diversity of forest ecosystems belonging to a particular forest type group.

The resulting curve of normal distribution and its main statistics in standardized variables are shown on Figure 7.

On Figure 7 the average value of distribution is situated at the beginning of the coordinates. The number of standard deviations from the average serves as a unit to measure alpha diversity.

As shown on the figure, $68.3 \%$ of forest ecosystems should have alpha-diversity comprised within the limits of one $\sigma, 95.4 \%$ in the limits of two $\sigma$, and $99.7 \%$ in the limits of three $\sigma$.

Standard of alpha diversity for forest ecosystems should be considered to be the mean value of alpha diversity for each forest type group - $m$; standard deviation, and standard curve are analytical tools for assessing deviations from the standard.

Standard curves for alpha diversity assessment of Karelian Isthmus forest 
ecosystems, belonging to the lichen-poorest and oxalis-richest in alpha diversity forest type groups are shown on Figure 8 and Figure 9.

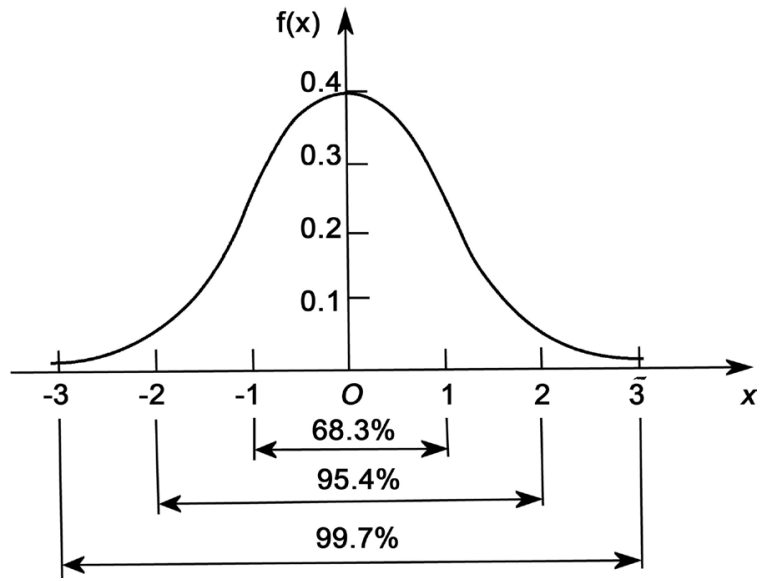

Figure 7. Curve of normal distribution and its main statistics in standardized variables.

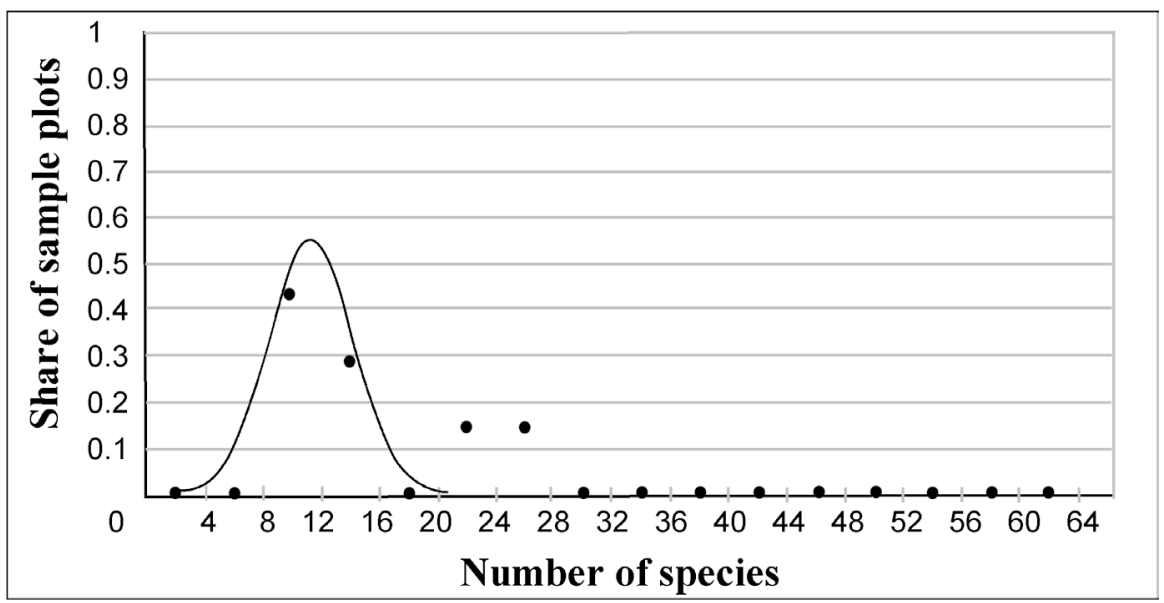

Figure 8. Share of sample plots with different alpha diversity in lichen forest type group (mean 11 species, standard deviation $2.9, \mathrm{R}^{2}=74.5 \%$ ).

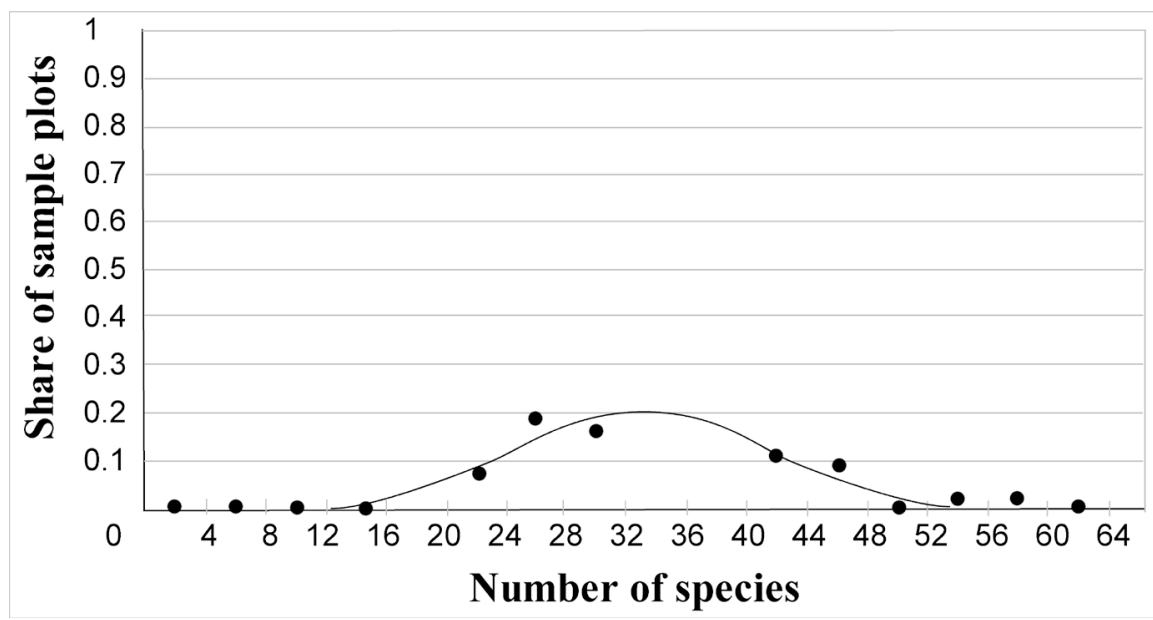

Figure 9. Share of sample plots with different alpha diversity in oxalis forest type group (mean 33 species, standard deviation $8.2, \mathrm{R}^{2}=93.5 \%$ ). 
Standard curves statistical characteristics for the all seven forest type groups, as well as the determination coefficient showing the quality in approximating experimental data with the normal distribution curve, are given in Table 2.

As shown in Table 2, as alpha-diversity mean value increases, the standard deviation also increases. Standard deviation will then have to be taken into account when using biodiversity standards for practical applications.

Practical use of the standard may be to assess alpha-diversity of particular natural areas by comparing observation results with awaited results of the standard. In order to use the standard for practical application, indicator variability within forest type groups has to be taken into account. This could be done the following way:

1) Choose from Table 2 the standard corresponding to the assessed forest type group;

2) Determine the difference (d) between the standard (average) value of alpha diversity and the measured one;

3) Determine how many times the difference $d$ exceeds the standard deviations by calculating the ratio $d / \sigma$;

4) Conclude about the conformity of the observed results to the standard as follows:

a) If $d / \sigma \leq \sigma$, observed results correspond completely to the standard,

b) If $1<d / \sigma \leq 2 \sigma$, observed results correspond to the standard,

c) If $2<d / \sigma \leq 3 \sigma$, observed results do not completely correspond to the standard,

d) If $d / \sigma>3 \sigma$, observed results are not corresponding to the standard.

Doing so, objective data may be obtained concerning the state of particular forest ecosystems using vegetation diversity indicators together with the standards worked out.

\section{Conclusions}

The work carried out allowed gathering rich experimental data and evaluating

Table 2. Statistical characteristics of alpha diversity standards according to forest type groups.

\begin{tabular}{cccc}
\hline \multirow{2}{*}{ Forest type groups } & \multicolumn{2}{l}{ Statistical descriptions } & $\mathrm{R}^{2}, \%$ \\
\cline { 2 - 3 } & $m$ & $\sigma$ & 74.5 \\
\hline Lichen & 11 & 2.9 & 94.5 \\
Cowberry & 16 & 5.2 & 90.8 \\
Oxalis & 33 & 8.2 & 58.2 \\
Motley grass & 37 & 11.1 & 93.0 \\
Bilberry & 23 & 6.0 & 80.5 \\
Polytrichosum & 21 & 6.0 & 87.6 \\
Sphagnum & 19 & 4.7 & \\
\hline
\end{tabular}


the state of the biodiversity over the Karelian Isthmus [29] [30]. These results may be used as thresholds to evaluate further changes in biodiversity over the same area. They also may be used to compare the richness of Karelian Isthmus forest habitats to other habitats of the region.

Standards worked out have deep potential for practical applications as they allow locating, identifying and evaluating changes in biodiversity and thus grounding biodiversity conservation policy. Locating the most significant changes will allow regional authorities focusing on the most degraded areas. Identifying changes will permit to identify factors responsible for affecting biodiversity and thus defining countermeasures. At last, evaluating changes will allow appreciate effectiveness of biodiversity conservation measures.

More precisely, results may be summarized as follows:

- Methodology for Assessment and Inventory of Forest Ecosystems Biodiversity is developed on the base of regular grid of sample plots ICP-Forests international program and appears to be effective enough to provide the statistically reliable data for different plant biodiversity characteristics calculations and following analysis.

- Statistical analysis of $\alpha$ diversity (species diversity) of Karelian Isthmus forest vegetation cover conducted for each forest type group has shown that distribution of sample plots according to species diversity values can be clearly described by a curve of normal distribution. The average of species number is not large and amounts to 26 species per sample plot. The average quadratic deviation has been calculated as 9.5 . Thus, about $2 / 3$ of sample plots have species diversity ranging from 15 to 35 species.

- Beta-diversity analysis of Karelian Isthmus forest vegetation cover has shown that diversity noticeably varies along a gradient of ecological factors determined by forest type groups. The largest species diversity is observed in rich and optimally moistened habitats, the smallest one in dry and poor habitats, and medium diversity in moist ones. Soil and moisture are key factors controlling biodiversity of forest communities.

- Gamma-diversity analysis of forest vegetation cover has shown that all the nine landscape units have approximately equal species diversity. It ranges on the average from 21 to 32 species. On the whole, if vegetation biodiversity varies according to landscapes, this variation is approximately twice less (from 0.7 to 1.0 ) than according to forest type groups (from 0.4 to 1.0 ). This is due to the fact that landscapes are large and heterogeneous units made of forest ecosystems belonging to different forest type groups.

- Biodiversity standards characterizing forest ecosystems alpha diversity are average value for each forest type group $(\mathrm{m})$, standard deviation $(\sigma)$, and standard curve. These standards, taken in their all, constitute an analytical tool for assessing alpha-diversity deviations from the standard.

\section{References}

[1] Secretariat of the Convention on Biological Diversity (2014) Global Biodiversity 
Outlook 4, Montréal, 155 p.

https://www.cbd.int/gbo/gbo4/publication/gbo4-en.pdf

[2] Hansen, M., Potapov, P., Moore, R., et al. (2013) High-Resolution Global Maps of 21st-Century Forest Cover Change. Science, 342, 850-853.

https://doi.org/10.1126/science.1244693

[3] Angelstam, P., Andersson, K., Axelsson, R., Elbakidze, M., Jonsson, B.G. and Roberge, J.-M. (2011) Protecting Forest Areas for Biodiversity in Sweden 1991-2010: The Policy Implementation Process and Outcomes on the Ground. Silva Fennica, 45, 1111-1133. https://doi.org/10.14214/sf.90

[4] Naeem, S., et al. (1994) Declining Biodiversity Can Alter the Performance of Ecosystems. Nature, 386, 734-737. https://doi.org/10.1038/368734a0

[5] Lawton, J.H. (1994) What Do Species Do in Ecosystems? Oikos, 71, 367-374.

[6] Grime, J.P. (1997) Biodiversity and Ecosystem Function. The Debate Deepens. Science, 277, 1260-1261. https://doi.org/10.1126/science.277.5330.1260

[7] Jones, S.G., et al. (1997) Positive and Negative Effects of Organisms as Physical Ecosystem Engineers. Ecology, 78, 1946-1957. https://doi.org/10.1890/0012-9658(1997)078[1946:PANEOO]2.0.CO;2

[8] Wilcove, D.S. (1990) Protecting Biodiversity in Multiple-Use Lands: Lessons from US Forest Service. Trends in Ecology \& Evolution, 4, 385-388.

https://doi.org/10.1016/0169-5347(89)90108-0

[9] Noss, R.F. (1990) Indicators for Monitoring Biodiversity: A Hierarchical Approach. Conservation Biology, 4, 355-364. https://doi.org/10.1111/j.1523-1739.1990.tb00309.x

[10] McKenney, D.W., et al. (1994) Towards a Set of Biodiversity Indicators for Canadian Forests. Proceedings of a Forest Biodiversity Indicators Workshop, Canadian Forest Service, Sault St. Marie, November 29-December 1, 1993, 16-27.

[11] Loiskekoski, M., et al. (1994) Sound Forestry-Sustainable Development. List of Criteria and Most Suitable Indicators. Ministerial Conference on the Protection of Forests in Europe, Helsinki.

[12] Angelstam, P. (1998) Towards a Logic for Assessing Biodiversity in Boreal Forests. In: Bachmann, P., Kohl, M. and Paivinen, R., Eds., Assessment of Biodiversity for Improved Forest Planning, Kluwer, 301-313. https://doi.org/10.1007/978-94-015-9006-8_29

[13] McGeoch, B., et al. (1998) Scaling up the Value of Bioindicators. Trends in Ecology \& Evolution, 13, 46-47. https://doi.org/10.1016/S0169-5347(97)01279-2

[14] Hansson, L. (2000) Indicators of Biodiversity: Recent Approaches and Some General Suggestions. In Indicators for Forest Biodiversity in Europe (BEAR). EC Specific RTD Programme CT-3575. Technical Report №1, 1-7.

[15] Groombridge, B. (ed.) (1992) Global Biodiversity: Status of the Earth's Living Resources. Chapman and Hall, London, $342 \mathrm{p}$.

[16] (1992) Convention on Biodiversity. https://www.cbd.int/convention/text/default.shtml

[17] Roberts, A.M. and Gillam, F. (1995) Patterns and Mechanisms of Plant Diversity in Forested Ecosystems: Implications for Forest Management. Ecological Applications, 5, 969-977. https://doi.org/10.2307/2269348

[18] Alekseev, A.S., Houix, J.P. and Gauberville, C. (2006) La diversite floristique des forets de l'Isthme de Carelie. Foret-Entreprise, 167, 29-32. 
[19] Alekseev, A.S. (2015) Forest Ecosystems Biodiversity Assessment and Inventory: Case Study for Karelian Isthmus of Leningrad Region, Russia. ICP Vegetation 28 th Task Force Meeting, Rome, 3-5 February 2015, 11.

http://icpvegetation.ceh.ac.uk/publications/documents/Programmeandbookofabstra cts28thICPVegetationTaskForcemeeting2015.pdf

[20] Tilk, M., Tullus, T. and Ots, K. (2017) Effects of Environmental Factors on the Species Richness, Composition and Community Horizontal Structure of Vascular Plants in Scots Pine Forests on Fixed Sand Dunes. Silva Fennica, 51, Article ID: 6986. https://doi.org/10.14214/sf.6986

[21] UNECE (1998) Manual on Methodologies and Criteria for Harmonized Sampling Assessment Monitoring and Analysis of the Effects of Air Pollution on Forests. Programme Coordinating Centers, Hamburg, 177 p. http://www.icp-forests.org

[22] Kimmins, J.P. (1997) Forest Ecology. 2nd Edition, Prentice Hall, Upper Saddle River, $596 \mathrm{p}$.

[23] Whittaker, R.H. (1975) Communities and Ecosystems. 2nd Edition, Macmillan Publishing Co., New York, 387 p.

[24] Pianka, E.R. (1978) Evolutionary Ecology. Harper and Row, New York, Hagerstown, San Francisco, London, 398 p.

[25] Odum, E.P. (1983) Basic Ecology. CBS College Publishing, New York, 689 p.

[26] Giller, P.S. (1984) Community Structure and the Niche. Chapman and Hall, London, New York, 184 p. https://doi.org/10.1007/978-94-009-5558-5

[27] Fahring, L. and Merriam, G. (2000) Mosaic Landscapes and Ecological Processes. Chapman and Hall, London, 293-308.

[28] Kirschfeld, P. (1979) Theorie und Praxis der Waldtypenlehre in der Sovjetunion. Mitteil. des Vereins für forstliche Standortkunde und Forstpflanzenzüchtung. Stuttgart, No. 27, 31-34.

[29] Alekseev, A.S., Grigorieva, S.O., Egorova, G.L., Egorov, A.A., Fedorchuk, V.N., Chernov, I.M. and Gauberville, C. (2001) Vegetative Diversity of Karelian Isthmus Forest Ecosystems as Indicator of Their Ecological State. Assessment, Conservation and Sustainable Use of Forest Biodiversity. Published by the Secretariat of the Convention on Biological Diversity, Technical Series No. 3, Montreal, 22-24.

[30] Alekseev, A.S., Grigorieva, S.O., Egorova, G.L. and Trteyfeld, R.F. (2002) Assessment of Forest Ecosystems Biodiversity. Saint-Petersburg, 72 p. 